\title{
AFRODITA EN VENECIA O LOS LÍMITES DE LA INTERPRETACIÓN: LA NOVELA LA TEMPESTAD DE JUAN MANUEL DE PRADA
}

\author{
Il y a plus affaire à interpréter les interprétations. \\ Montaigne, Essais III/13
}

"Habia viajado a Venecia en busca de un cuadro que conocía sólo a través de reproducciones fotográficas..." $(12)^{1}$ se lee en las primeras páginas de la novela de Juan Manuel de Prada, que se desarrolla ante un trasfondo invernal decadentista en la ciudad de Venecia. El protagonista del texto es Alejandro Ballesteros, joven profesor universitario y especialista en arte, que nos va a preocupar en su función particular de yo-narrador, personaje-generador de la novela y sobre todo en su función de 'mitógrafo' para decirlo con las palabras de Ulrich Prill. ${ }^{2}$ El mitógrafo, según él, es el que al transformar e interpretar los elementos de un mito, al mismo tiempo los reconstruye y reproduce. El tema de nuestro artículo será entonces la revitalización, la reduplicación y la superposición de mitemas, discursos y estructuras literarias en una novela española del año 1997, premiada con el Planeta en el mismo año, una novela que -dicho sea de paso- provocó una fuerte polémica entre los críticos... ${ }^{3}$

La secuencia citada del principio de la novela nos conduce directamente all tema central del texto, es decir al famoso cuadro La Tempesta ${ }^{4}$ de Giorgione que igualmente sirve de titulo a la obra y que de este modo subraya su función generadora.

La presencia de motivos iconográficos y de cuadros concretos como parte estructuradora o temática de la diégesis es un fenómeno literario convencional que no tiene límites de época o de género y que se manifiesta como una constante metahistórica en literatura. La misma observación es válida a propósito de los mitos: la relación entre mito y literatura es una constante en la historia de la creación literaria. La literatura se caracteriza por una continua "Arbeit am Mythos" (labor en el mito), es decir por una continua reescritura del mito, para decirlo con las palabras de Hans Blumenberg. ${ }^{5}$

Sobre la reciprocidad de las relaciones entre literatura y arte se fundamenta la teoría de la intermedialidad. En el análisis de las posibles manifestaciones en las que la iconografia y la literatura aparecen relacionadas, partimos de la idea que en este contexto ha planteado Volker

\footnotetext{
1 Las páginas indicadas en el texto se refieren a la primera edición de la novela, publicada en Barcelona en la editorial Planeta, en noviembre de 1997.

2 Véase Prill, Ulrich: “Wer bist du - alle Mythen zerrinnen". Benito Pérez-Galdós als Mythograph und Mythoklast. Bern: Peter Lang, 1999.

3 Véase p. ej. Rafael Conte en ABC literario, 7.11.1997, p. 11, J. Ernesto Ayala-Dip en El Pais, Babelia, 8. 11. 1997, p. 13 o Paul Ingendaay en Frankfurter Allgemeine Zeitung, 7.8.1999, p. 38.

4 Para distinguir el titulo de la novela del título del cuadro este último se cita en su forma italiana. La propia novela habla en los dos casos de La tempestad.

5 Véase Blumenberg, Hans: Die Arbeit am Mythos. Frankfurt am Main: Suhrkamp 1979.
} 
Roloff: la influencia reciproca entre la imagen y la palabra o la imagen y el texto es la base fundamental de cualquier producción y recepción estética. ${ }^{6}$

La situación estructural de la novela La tempestad es la siguiente: el cuadro es el generador del texto y el centro de la polémica interpretativa de los protagonistas del mismo. Dicho desde la perspectiva de la estética de la producción: se trata de la presencia de una obra de arte en un texto literario, en particular de un cuadro auténtico en un texto ficcional. Dentro de la novela, el cuadro está en el mismo rango y en el mismo nivel diegético que los protagonistas, el cuadro aparece en forma ficcionalizada y su autenticidad extraliteraria no tiene ninguna importancia, ni en el argumento ni en la recepción de la novela. Mencionemos por lo menos un intertexto con una situación paralela: la novela decadentista de Joris-Karl Huysmans, $A$ rebours. En ambas novelas la contemplación de obras de arte, su descripción y su interpretación constituyen el tema central de los textos. En $A$ rebours las obras de la galería privada del protagonista Des Esseints son las representaciones de Salomé de Gustave Moreau y otras obras de van Luyken, Bresdin, Durero, Redon, Goya y Ticiano. En La tempestad-conforme a las exigencias de una aparente novela policíaca- las obras discutidas, restauradas, robadas y falsificadas son de Giorgione, Delvaux, Bellini y Tintoretto.

El universo narrativo de la novela de Juan Manuel de Prada es Venecia, en concreto el arte veneciano, más concretamente el cuadro de Giorgione. Para el antagonista femenino de Alejandro Ballesteros, la restauradora Chiara que representa un tipo de 'femme fatale', La Tempesta es la metáfora del "misterio de Venecia" (149). Al mismo tiempo y según las exigencias del cliché literario de la 'femme fatale' - la cuarentona diva Giovanna Zanon la nombra "Lolita" (128) - el falsificador de arte Fabio Valenzin se apasiona por su alumna Chiara y la convierte en el modelo de su falsificación de La Tempesta. De este modo, Chiara entra en el universo del cuadro. Ballesteros reflexiona sobre la relación entre Valenzin, Chiara y el cuadro:

Quizá Valenzin, al retratar a Chiara en la misma postura que Giorgione eligió para inmortalizar a la mujer de su cuadro, había querido preservarla intacta, en un ejercicio de reverencia admirativa, suspenderla en un ámbito de intangibilidad. (236)

El tercer hombre significativo en torno a Chiara es el director de la Academia de Venecia, lugar del cuadro en cuestión, del que el director Gabetti se convierte en protector, como si fuera el santo Grial. Gilberto Gabetti vive con su hija adoptiva Chiara en un antiguo palacio veneciano. También él traspone sus deseos al cuadro de Giorgione y se ve personificado en él:

Gilberto [...] una vez se comparó con el personaje de ese cuadro de Giorgione, $[\ldots]$ atento sólo a la niña que crecía y se iba haciendo adulta, según las directrices que él le había marcado, aunque a su alrededor el paisaje anunciase tormenta. (131)

6 Véase Volker Roloff en Strosetzki/Stoll: "[d]ie Wechselbeziehung zwischen Bild und Sprache bzw. zwischen Bild und Text [ist] für jede Produktion und Rezeption grundlegend [...]" (1993:1). 
Por último, Alejandro Ballesteros, que en su función de yo-narrador guía el discurso, se identifica tanto con el cuadro que también se ve reflejado en él hasta comparar toda su vida con una pintura:

[...] mi profesión consiste en mirar cuadros, que son compartimentos donde la realidad se ensimisma, o quizá porque mi vida también era ensimismada como un cuadro, me abrumaba este trasiego de vecindades, invisible a primera vista. (101)

En sus sueños y en sus pesadillas el papel de la figura femenina de La Tempesta -una mujer desnuda que está amamantando a un niño - se lo atribuye como todos los demás hombres a Chiara. Chiara se convierte en el 'objeto de su deseo'; para Ballesteros es ella quien representa "el misterio de Venecia, tenía su misma belleza herida" (150). El latente discurso erótico se manifiesta siempre a través del cuadro, es decir: el discurso erótico está unido al discurso artístico y los dos están determinados por el espacio narrativo en el que la novela está situada: Venecia. En la recepción de la literatura moderna el nombre de Venecia evoca por fuerza un discurso literario concreto: el discurso decadentista, entendido, claro está, como fenómeno metahistórico. Pensemos p. ej. en artistas como Gabriele D’Annunzio, Thomas Mann o Richard Wagner, para mencionar sólo algunos. Basta echar un vistazo a los dos temas centrales de la novela que acabamos de esbozar: el arte y el amor. Con el motivo del asesinato del falsificador de arte se une el tercer tema, el tema de la muerte. Esta muerte es una muerte en Venecia que se esconde detrás de una máscara del médico de là peste, es un 'Liebestod' causado por un amor en agonía. Sin embargo no se trata de una muerte sublimada como en la ópera wagneriana, sino de una muerte de tipo policíaco, es decir aparece de forma más materializada para no decir desacralizada. Chiara se autoestiliza en ángel de la guarda de Venecia y no puede aceptar que Fabio Valenzin robe el cuadro de La Tempesta para venderlo. Para evitar el sacrilegio, Chiara mata a Valenzin, su amante. El motivo decadentista predilecto de la unión de Eros y Thanatos se revela más que obvio. Una vez más, de los tres temas centrales, el arte es el predominante bajo el que se subsumen el amor y la muerte, lo cual se manifiesta por excelencia en el episodio mencionado. Al confesar su crimen a Ballesteros, Chiara le explica que prefiere el arte a la vida, expresión de su deformación artística pervertida: "Nadie mata lo que ama, salvo si nos mueve otro amor más fuerte" (311). Este amor más fuerte es su amor por el cuadro de Giorgione y por el arte veneciano, por eso el ángel de la guarda se convierte en un ángel del Juicio Universal. El Juicio Universal es a la vez un motivo constante de la novela que aparece en forma del cuadro de Tintoretto que Chiara está restaurando en la iglesia Madonna del Orto. En otras palabras y visto desde la perspectiva de la estética de la producción: de la misma manera que La Tempesta es el leitmotiv del texto, el Juicio Universal es un 'Nebenmotiv' (motivo adicional) que anticipa los acontecimientos de la novela. Y otra vez en el nivel de la producción literaria, la decisión de optar por el arte y renunciar a la vida es uno de los motivos predominantes de la estética decadentista.

Antes de concluir nuestras primeras observaciones fijémonos en el nivel estructural de la novela. La estructura del texto está marcada por el procedimiento de la 'mise en abîme'. Entendemos el término de 'mise en abîme' en el sentido de André Gide que, dicho en pocas 
palabras, lo definó como "l'œuvre dans l'œuvre" (obra dentro de la obra). Se trata de una reduplicación especular de estructuras y motivos artísticos en la propia obra. ${ }^{7} \mathrm{Al}$ aplicar el procedimiento de la 'mise en abîme' a la novela La tempestad la estructura será la siguiente:

1) el título de la novela es igual al título del cuadro, es decir: La Tempesta está dentro de La tempestad; 2) El cuadro se encuentra en el museo de la Academia de Venecia y, según la interpretación de Chiara, representa el misterio de Venecia; en otras palabras: el cuadro de La Tempesta es un espejo de la ciudad de Venecia; 3) los personajes de la novela se identifican con las personas representadas en el cuadro, lo cual significa que los protagonistas se ven reflejados en el cuadro. Resumamos: El movimiento del texto conduce al interior del mismo, está dirigido hacia sí mismo. Dicho de otro modo: la actitud del texto es autorreflexiva, autoconsciente y narcisista. Una tal actitud es una de las características de la novela metaficcional, como lo ha señalado entre otros Linda Hutcheon en su estudio Narcissistic Narrative. The Metafictional Paradox..$^{8} \mathrm{El}$ procedimiento de la 'mise en abîme' sirve para descubrir el carácter metaficcional y para aclarar la estructura especular y narcisista del texto.

Hagamos un primer balance. El cuadro La Tempesta es el espejo de todos los protagonistas, mejor dicho: se convierte en el fetiche de todos ellos. El yo-narrador de la novela nota el mismo efecto en las personas que intentan apropiarse del cuadro, sea de forma intelectual o material:

La tempestad, ese cuadro que yo había diseccionado y recompuesto con paciencia numismática, no era sólo un objeto de disfrute estético, [...] también era el campo de batalla donde [...] hombres y mujeres dirimían sus conflictos, el escenario donde se explicaban sus quimeras y anhelos y frustraciones. (186)

La Tempesta es el objeto de culto de los protagonistas, lo admiran en una especie de religiosidad que se concreta en una frase clave del texto: el arte es "la religión del sentimiento" (67). No todos están convencidos de esta opinión: Ballesteros "el intruso" (17), incrédulo al principio, deja de ser el investigador racional y opta al final por la "comprensión" en vez del "entendimiento" (321) del arte. El Judas entre los apóstoles es el falsificador Fabio Valenzin, pero al desacralizar el cuadro comete un sacrilegio y será castigado. Por eso lo mata Chiara en su función de ángel del Juicio Universal.

Dejando de lado el campo semántico de la terminología cristiana y volviendo al término del 'fetiche' nos estamos acercando al campo mitológico del discurso narrativo. Según la definición de la Real Academia Española, el fetiche es "Idolo u objeto de culto al que se atribuye poderes sobrenaturales [...]". ${ }^{9} \mathrm{El}$ fetichismo por consecuencia es el "culto de los fetiches", o en el sentido figurativo "Idolatría, veneración excesiva". En el contexto de la psicología se entiende bajo fetichismo una "desviación sexual que consiste en fijar alguna parte del cuerpo humano o alguna prenda relacionada con él como objeto de la excitación y el deseo". ${ }^{10}$ Salta a la vista que en

\footnotetext{
7 Véase igualmente Dällenbach, Lucien: Le récit spéculaire. Essai sur la mise en abime. Paris: Seuil, 1977.

8 Primera edición en Wilfrid Laurier University Press, Waterloo, Ontario, Canada 1980.

9 Véase: Diccionario de la Real Academia Española 1992, vol. I, p.961.

10 Ibid.
} 
los pasajes citados de la novela el cuadro aparece calificado de "ejercicio de reverencia admirativa" (236), "objeto de disfrute estético" (186), "escenario donde se explicaban sus quimeras y anhelos y frustraciones" (186). Al mismo tiempo para los aficionados del cuadro La Tempesta es el sujeto de sus sueños. Todo esto lo convierte en un simulacro de un 'fetiche'. La polivalencia del término con sus facetas religiosas, estéticas y eróticas subraya a la vez el carácter predominante del cuadro que entra en la condición humana de los personajes novelescos y, en el nivel metaficcional, conduce a la estilización y a la sublimación, a las propias categorías artísticas.

Polivalencia y una calidad polifacética condicionan igualmente el carácter abierto de la recepción mitológica, como ya ha señalado Ulrich Prill:
Wird ein Mythos -in welcher Form auch immer-rezipiert, so erfährt dadurch ein Text (oder ein Kunstwerk im allgemeinen) nicht unbe- dingt, wie man annehmen könnte, eine Überhöhung oder Verklärung, sondern gewinnt vor allem an Polyvalenz. ${ }^{11}$

A continuación nos dedicaremos a la lectura mitológica de $L a$ Tempesta elaborada por el protagonista de la novela. Alejandro Ballesteros, trás la disección y recomposición del cuadro, presenta su primer gran esfuerzo de investigación académica que consiste en una lectura mitológica de La Tempestad. Sus antecesores habian descubierto la historia de "Moisés rescatado de las aguas" (13), "Paris alimentado por una osa bajo especie humana" (13), el "descanso de San José y la Virgen, en su huida a Egipto" (13) y un sinfin de interpretaciones más de las que ninguna está considerada la más convincente. Al buscar la correspondencia entre las figuras de la mitología griega y los respectivos personajes y sus atributos simbólicos del cuadro surge la siguiente interpretación:

\begin{abstract}
Zeus procuró por todos los medios acostarse con su hija Afrodita, pero sus requiebros y hechizos no surtieron el efecto deseado; Afrodita no cedía al cortejo paterno, y entonces Zeus, para humillarla, hizo que se enamorara de un mortal. [...] Zeus eligió como instrumento de su castigo al bello Anquises, rey de los dárdanos, que también fue joven e inexperto [...]. (167)
\end{abstract}

Todo el capitulo 7 de la novela cuenta la vanidosa disputa entre el director de la Academia que defiende la imposibildad y el sinsentido de cualquier interpretación del cuadro ("Sigo pensando que La tempestad no responde a ningún tema concreto, sino a una intuición del sentimiento [...], 170) y la lectura mitológica de La Tempesta por parte de Ballesteros que en este contexto es el mitógrafo. Entre Ballesteros y Gabetti está Chiara que resume la síntesis iconográfica del cuadro:

La mujer desnuda, entonces, sería Afrodita, amamantando a Eneas; en su actitud hay cierta indiferencia hacia el hombre que la observa, a

11 Prill (1999:23): “En la recepción de un mito - sea de la forma que sea- el texto (o la obra de arte en general) no se trasforma necesariamente en algo sublimado o elevado como se podría pensar. En primer lugar el texto gana en polivalencia." 
quien ni siquiera le devuelve la mirada: muy bien podría ser ese gesto de "tímida aversión" al que tú aludes. [...] El peregrino que la contempla con tristeza está claro que se corresponde con Anquises; el báculo o bordón sería el simbolo de su condena. Desde el cielo, Zeus descarga su ira. (169)

El núcleo del mito referido es un intertexto no marcado concreto: se trata de Los himnos homéricos, en particular del himno $\mathrm{V}$, dedicado "A Afrodita". En contraposición a la minuciosa interpretación de Ballesteros que incluye todos los detalles del cuadro en su lectura mitológica - "Las columnas rotas representan el amor arruinado entre Afrodita y Anquises. [...] También podrían ser un augurio de la destrucción de Troya." (170)- está la convicción de Gabetti de que la

fascinación [del cuadro] deriva de su desafio a la lógica, del extraño aislamiento de las figuras, de la tormenta que se larva y no llega a desencadenarse. (170)

Aunque los mitemas de la historia entre Afrodita y Anquises - sirviéndonos de la terminología de Claude Lévi-Strauss - están presentes en el cuadro y se muestran de modo coherente, Ballesteros siente cierto afán frente al concepto estético del director Gabetti:

Aunque la victoria me pertenecia, reconoci para mis adentros que el misterio es siempre superior a su resolución: el misterio nos aproxima a lo sobrenatural; su resolución, a lo puramente mecanisista. (171)

En sus sueños perdura su lectura homérica del cuadro, pero en otro contexto. Como es bien sabido, una de las características de los mitemas es su flexibilidad en la combinación, su disposicón a colocarse fragmentariamente en textos literarios. Es decir el mito y sus mitemas invitan a la ars combinatoria (Prill). ${ }^{12} \mathrm{El}$ discurso onírico tal como se manifiesta en La tempestad, dispone de los mitemas del himno $\mathrm{V}$ de Homero situándolos en el contexto de la experiencia vital del yo narrador. Alejandro Ballesteros se ve reflejado en el cuadro de La Tempesta y se identifica con el personaje masculino. En el primer nivel descriptivo del cuadro, el hombre es un peregrino ("un hombre ataviado según la moda de la época y con bordón de peregrino”, 12), según la interpretación de Ballesteros representa a Anquises. En la primera secuencia onírica del texto, al yo-narrador se le aparece "el escenario de La tempestad. [...] Yo era el peregrino. [...] y la mujer [...] era Chiara" (79s). Luego Ballesteros sueña de nuevo con el cuadro, esta vez en forma de una pesadilla: "Yo volvía a pasearme por el paisaje de La tempestad, del que habían desertado las figuras [...]" (282). En esta secuencia se muestra la típica estructura discontinua y alógica del discurso onírico que se vacía de toda referencialidad. Por último, el discurso onírico interviene en el diálogo de despedida entre Ballesteros y Chiara en el que la referencia a la interpretación mitológica de Ballesteros aparece de forma marcada:

12 Véase Prill (1999:25) 
La obedeci, aunque las rodillas me temblaban, como debieron de temblarle a Anquises cuando el rayo de Zeus lo hirió y ya nunca más pudo mantenerse erguido sin ayuda de un báculo. (319)

En esta cita la 'Configuratio personae' disuelve por completo las diferencias entre los personajes novelescos, las personas representadas en el cuadro y las figuras mitológicas entradas en el cuadro a través de la interpretación. Alejandro Ballesteros es al mismo tiempo el profesor universitario, el peregrino y la figura mitológica. Paralelamente, Chiara es la restauradora de cuadros, el modelo de la figura femenina de La Tempesta y a la vez la encarnación de Afrodita, según la lectura mitológica. El papel de Afrodita en el intertexto homérico se superpone con el papel de la 'femme fatale' que ocupa Chiara dentro de la novela. El atributo común de ambas es su capacidad de seducción; dicho desde la perspectiva de la estética de la producción, su valencia erótica en el texto. El discurso mitológico abre la novela hacia la polivalencia y la recomposición de los mitemas de manera que el personaje principal femenino del texto, Chiara, tiene a la vez el papel de Afrodita y el del ángel del Juicio Universal. Junto con la superposición palimpséstica de los papeles literarios se superponen a la vez los discursos novelescos: el discurso pictórico, erótico, decadentista, metaliterario y varios más que no hemos mencionado aquí. El discurso policíaco p. ej. tiene una importancia constitutiva en el texto, pero al mismo tiempo sirve simplemente de pretexto para mantener el suspense en una novela que en primer lugar pretende establecer un ambiente artístico predominante y una ocupación por la estética y su puesta en escena. A la base de la continua interpretación pictórica y la disputa intelectual se genera el discurso metaficcional de La tempestad bajo el que todos los discursos analizados se dejan subsumir. La novela de Juan Manuel de Prada es por el tema del arte, por la polivalencia de las interpretaciones artísticas, por su estructura de 'mise en abîme', por su actitud autocrítica y autorreflexiva una novela intermedial y metaficcional por excelencia.

Desde la perspectiva de la estética de la recepción el propio texto provoca la puesta en duda de las sofisticadas y rebuscadas explicaciones interpretativas y los esfuerzos intelectuales de la crítica o la teoría literaria. El narcisismo literario resulta a la vez una actitud productiva y receptiva que tiene un objetivo común: el disfrute estético o para decirlo con las palabaras de Roland Barthes: "la jouissance narrative". ${ }^{13}$ Como dice Jacques Lacan: "[...] lire ne nous oblige pas du tout à comprendre. Il faut lire d'abord". ${ }^{14}$ Gocemos entonces de la literatura. Para analizarla nos queda tiempo.

\footnotetext{
13 Véase Barthes, Roland: Le plaisir du texte. Ed. du Seuil, 1973.

14 Véase Lacan, Jacques: Le Séminaire. Livre XX. Paris: Ed. du Seuil, 1975:61.
} 


\section{AFRODITA V BENETKAH ALI MEJE INTERPRETACIJE: ROMAN NEVIHTA (LA TEMPESTAD) JUANA MANUELA DE PRADE}

Roman Juana Manuela de Prade je tematsko povezan z Benetkami in znano Giorgionejevo sliko La Tempesta. Zaradi polivalentnosti umetniških interpretacij, strukture 'mise en abîme', kritičnega stališča do literarne interpretacije in razmišljanja o romanu kot kreativnem postopku je Nevihta prvovrstno metafikcijsko delo. Sofisticirane interpretacije in intelektualni napori literarne kritike in teorije vzbujajo precej dvomov s stališča estetike recepcije. Jacques Lacan pravi: "[...] lire ne nous oblige pas du tout à comprendre. Il faut lire d'abord." Torej je treba literaturo predvsem brati in se je veseliti, za analizo je vedno dovolj časa. 